\title{
Prediction of the Standard Gibbs Energy of Ion Transfer across the 1,2-Dichloroethane/Water Interface
}

\author{
Akiyoshi Yamada, Erina Yoshida, Kazuo Eda, and Toshiyuki OsaKaI ${ }^{\dagger}$ \\ Department of Chemistry, Graduate School of Science, Kobe University, Nada, Kobe 657-8501, Japan
}

\begin{abstract}
The standard Gibbs energy of ion transfer at the 1,2-dichloroethane/water interface $\left(\Delta G_{\mathrm{tr}}^{\mathrm{o}} \mathrm{W} \rightarrow \mathrm{O}\right)$ was determined for 26 organic cations and 24 anions by means of ion-transfer voltammetry with a micro oil/water interface. Based on the data sets, a theoretical analysis was performed with the non-Bornian solvation model, in which the solvation energy of an organic ion is evaluated from local electric fields on the surface of the ion. The semi-empirical equations thus obtained are available for relatively accurate prediction of $\Delta G_{\mathrm{tr}}^{\mathrm{o}} \mathrm{W} \rightarrow \mathrm{O}$ for organic ions. The mean absolute error was 1.9 or $3.1 \mathrm{~kJ} \mathrm{~mol}^{-1}$ for cations or anions, respectively, corresponding to the error of $\sim 20$ or $\sim 30 \mathrm{mV}$ in the standard ion-transfer potential. In this paper, energy decomposition has been performed to discuss different contributions to $\Delta G_{\mathrm{tr}}^{\mathrm{O}}, \mathrm{W} \rightarrow \mathrm{O}$ from the "hydrated" (strongly charged) and positively and negatively charged "non-hydrated" (moderately charged) surfaces as well as from the hydrophobic interaction (cavity formation energy).
\end{abstract}

Keywords Standard Gibbs energy, ion transfer, 1,2-dichloroethane/water interface, non-Bornian theory

(Received February 27, 2018; Accepted April 6, 2018; Advance Publication Released Online by J-STAGE June 10, 2018)

\section{Introduction}

The standard Gibbs energy of ion transfer $\left(\Delta G_{\mathrm{tr}}^{\mathrm{o}, \mathrm{W} \rightarrow \mathrm{O}}\right)$ across the organic solvent or oil $(\mathrm{O}) /$ water $(\mathrm{W})$ interface, in other words, the interface between two immiscible electrolyte solutions (ITIES), is important for understanding the transport, distribution, and adsorption of ions in two-phase systems including solvent extraction, phase-transfer catalysis, membrane transport, emulsion, and possibly biomembranes. ${ }^{1,2}$ So far, theoretical studies of $\Delta G_{\mathrm{tr}}^{\mathrm{o}, \mathrm{W} \rightarrow \mathrm{O}}$ have been performed mainly based on Born-type electrostatic solvation models. ${ }^{3-6}$ In the classical Born model, ${ }^{3}$ the ion-transfer energy is considered as a difference between electrostatic energies for charging a spherical ion up to $z e$ ( $z$ is the charge number including the sign; $e$ is the elementary charge) in $\mathrm{O}$ and $\mathrm{W}$. However, the Born model cannot predict the values of $\Delta G_{\mathrm{tr}}^{\mathrm{o}}, \mathrm{W} \rightarrow \mathrm{O}$ very well, and some attempts have been made to improve the model by considering the dielectric saturation (i.e., the lowering of the permittivity of solvents adjacent to an ion due to the high electric field). ${ }^{46}$ In one of the most frequently cited modifications (the AbrahamLiszi model) ${ }^{4}$ it is assumed that a local solvent layer around an ion has a very low dielectric constant, i.e., $\varepsilon_{1}=2$ (cf. $\varepsilon=\sim 80$ for bulk water). This suggests that the contribution from the primary solvent layer, or, the short-range ion-solvent interaction should be much more significant than the long-range electrostatic interaction.

Our group has proposed a non-Bornian model, in which $\Delta G_{\mathrm{tr}}^{\mathrm{o}, \mathrm{W} \rightarrow \mathrm{O}}$ is formulated by considering only short-range interactions of an ion and solvent molecules (which include Coulomb, polarization, and charge-transfer interactions) ${ }^{7-9}$ For

† To whom correspondence should be addressed.

E-mail: osakai@kobe-u.ac.jp the ions that are spherical or may be assumed as such (i.e., for mainly inorganic ions), the $\Delta G_{\mathrm{tr}}^{\mathrm{o}} \mathrm{W} \rightarrow \mathrm{O}$ scaled by the ionic surface area can be given by a quadratic function of the surface field strength of the ion, $E$ ( $=z e / 4 \pi \varepsilon_{0} r^{2}$, where $r$ is the ionic radius, and $\varepsilon_{0}$ is the permittivity of vacuum). However, the three coefficients of the quadratic function are difficult to determine accurately from a purely theoretical approach. In the previous studies, ${ }^{7,8}$ therefore, several sets of the coefficients were successfully obtained by regression analyses using experimental values of $\Delta G_{\mathrm{tr}}^{\circ}, \mathrm{W} \rightarrow \mathrm{O}$ for different ion groups, including hydrophilic cations and anions, hydrophobic cations and anions, and polyoxometalate anions. In the analysis of the hydrophilic ions, however, the coextraction of water molecules, ${ }^{10,11}$ or, the selective hydration of ions in the $\mathrm{O}$ phase, should be considered in the estimation of $E$; that is, it is assumed that the "hydrated" ion is the transferring ion and we should obtain the radius of the hydrated ion using the number of coextracted water molecules.

Such an approach as described above cannot be directly applied to organic ions having charged groups (e.g., $-\mathrm{SO}_{3}^{-}$, $\left.-\mathrm{CO}_{2}^{-},-\mathrm{NH}_{3}{ }^{+}\right)$. The surface field strength of these ions is not uniform; the surface of a charged group has a strong electric field, whereas the surface of an uncharged moiety (e.g., alkyl chain, benzene ring) has a weak field. In the previous study, ${ }^{9}$ we evaluated the local electric field ( $E_{\mathrm{i}}$ with $\left.i=1,2,3 \cdots\right)$ on a minute surface of an ion by means of a DFT calculation with a developed subprogram. ${ }^{12}$ Then, we employed the non-Bornian solvation model to perform regression analyses with the values of $\Delta G_{\mathrm{tr}}^{\mathrm{o}} \mathrm{W} \rightarrow \mathrm{O}$ measured or reported for the nitrobenzene (NB)|W system. Good regression results were obtained with the mean absolute error (MAE) of 1.9 and $2.4 \mathrm{~kJ} \mathrm{~mol}^{-1}$ for 34 anions and 63 cations, respectively. These errors correspond to the error of $\sim(20 / z) \mathrm{mV}$ in the standard ion-transfer potential, $\Delta_{\mathrm{O}}^{\mathrm{W}} \phi^{\circ}$ $\left(=\Delta G_{\mathrm{tr}}^{\mathrm{o}, \mathrm{W} \rightarrow \mathrm{O} / z F}\right)$, being only two times larger than the typical experimental error, $\sim(10 / z) \mathrm{mV}$, in the voltammetric measurement. 
In this study, we have extended our non-Bornian approach to the 1,2-dichloroethane (DCE)/W system. The DCE/W system as well as the NB/W system has been extensively used for electrochemical measurements. Because DCE is redox inactive, a variety of electron-transfer reactions have been studied in the DCE/W system. ${ }^{13-17}$ Furthermore, since DCE has no absorption in the visible light region, the DCE/W system is suitable for spectroelectrochemical measurements ${ }^{18-21}$ and also for studies of photo-induced electrochemical reactions. ${ }^{22-25}$ Thus, it would be useful to predict $\Delta G_{\mathrm{tr}}^{\mathrm{o}, \mathrm{W} \rightarrow \mathrm{O}}$ values for ions at the DCE/W interface by using a theoretical method. However, DCE has a lower permittivity $\left(\varepsilon=10.37\right.$ at $25^{\circ} \mathrm{C}$ ) than $\mathrm{NB}$ (with $\varepsilon=34.78$ ), so that accurate determination of $\Delta G_{\mathrm{tr}}^{\mathrm{o}, \mathrm{W} \rightarrow \mathrm{O}}$ may not be performed because of possible ion-pair formation in the DCE phase. In this study, we have used an extremely low concentration of the supporting electrolyte $\{1.0 \mathrm{mM}$ of bis(triphenylphosphoranylidene)ammonium tetrakis(4-chlorophenyl)borate; BTPPATCIPB in DCE and have obtained moderately accurate values of $\Delta G_{\text {tr }}^{\circ}, \mathrm{W} \rightarrow \mathrm{O}$ for 26 cations and 24 anions by means of a previously reported voltammetric technique with a micro O/W interface. ${ }^{11}$ Regression analysis based on the non-Bornian solvation model was successfully performed.

\section{Theoretical Model}

In this study, the same theoretical model as described previously ${ }^{9}$ has been used, which will be described in short below. The Gibbs solvation energy $\left(\Delta G_{\mathrm{S}}^{\circ}\right)$ of an ion in solvent $\mathrm{S}$ is regarded as the energy required for the formation of a nanosized ion-solvent interface around the ion. By generalizing the Uhlig formula, ${ }^{26}$ we obtain:

$$
\Delta G_{\mathrm{S}}^{\circ}=\int_{\mathrm{S}_{0}} \gamma_{12} \mathrm{~d} S
$$

where $S_{0}$ is a closed surface enclosing the ion, $\mathrm{d} S$ is an infinitesimal area on $S_{0}$, and $\gamma_{12}$ is the surface tension of the solvent (2) on the charged ion (1). Then, it is assumed that $\gamma_{12}$ is related to the work of adhesion $\left(W_{12}\right)$ by the Dupré equation, ${ }^{27}$

$$
\gamma_{12}=\gamma_{1}+\gamma_{2}-W_{12}
$$

where $\gamma_{1}$ and $\gamma_{2}$ are the "hypothetical" surface tension of the ion in vacuum and that of the solvent with its own vapor, respectively. It is also assumed for simplicity that the opposite sign of $W_{12}$ is given by multiplying the energy of the short-range ion-solvent 1:1 interaction $\left(U_{\mathrm{SR}}\right)$ by the number $(N)$ of primary solvent molecules in the unit surface area of the ion. Therefore,

$$
\gamma_{12}=\gamma_{1}+\gamma_{2}+N U_{\mathrm{SR}}
$$

Substituting this equation into Eq. (1) yields

$$
\Delta G_{\mathrm{S}}^{\circ}=\int_{\mathrm{S}_{0}}\left(\gamma_{1}+\gamma_{2}+N U_{\mathrm{SR}}\right) \mathrm{d} S
$$

Referring to the energy decomposition analysis in ab initio self-consistent molecular orbital studies, ${ }^{28-30} U_{\mathrm{SR}}$ can be partitioned into Coulomb (COU), polarization (POL), chargetransfer $(\mathrm{CT})$, and exchange (EX) terms. The COU and POL terms correspond to empirical ion-dipole and ion-induced dipole interactions; the CT term is due to a partial electron transfer between an ion and solvents in its vicinity; the EX term is a non-classical, electron-exchange repulsion energy. These terms are given by a linear or quadratic function of $E$, though the EX term is assumed to be independent of $E$. Consequently, is expressed by

$$
\Delta G_{\mathrm{S}}^{\circ}=\int_{\mathrm{S}_{0}}\left(-A-B E-C E^{2}\right) \mathrm{d} S
$$

with

$$
\begin{aligned}
& A=N \zeta_{0}-N U_{\mathrm{EX}}-\gamma_{1}-\gamma_{2}, \\
& B=N \mu\langle\cos \theta\rangle+N \zeta_{1}, \\
& C=(1 / 2) N \alpha+N \zeta_{2},
\end{aligned}
$$

where $\mu$ and $\alpha$ are the dipole moment and electronic polarizability of the solvent molecule, respectively, $\theta$ is the angle between the dipole axis and the line connecting the point dipole and point charge, \langle\rangle indicates the ensemble average, and the CT coefficients of $\zeta_{0}, \zeta_{1}$, and $\zeta_{2}$ are influenced by various molecular properties of both the solvent and ion, including their electron-donating or -accepting abilities. Thus, these CT coefficients are inherently specific not only to the ion but also to the solvent. However, empirically we know that the contribution from the electrostatic (COU and POL) interactions is much more significant than that from the ion-specific CT interaction (and probably also from $\gamma_{1}$ ). Consequently, we can assume that the coefficients, $A, B$, and $C$, given by Eqs. (6) - (8), are common to ions, or, only specific to the solvent.

In the numerical calculation of $\Delta G_{\mathrm{S}}^{\circ}$, the closed surface $S_{0}$ is divided into a finite number of minute surface elements (whose surface area is denoted by $S_{\mathrm{i}}$ with $\left.i=1,2,3 \cdots\right)$. Then, the value of $\Delta G_{\mathrm{S}}^{\circ}$ can be obtained as:

$$
\begin{aligned}
\Delta G_{\mathrm{S}}^{\circ}=\sum S_{\mathrm{i}}\left(-A-B E_{\mathrm{i}}-C E_{\mathrm{i}}^{2}\right) & = \\
& -A \sum S_{\mathrm{i}}-B \sum S_{\mathrm{i}} E_{\mathrm{i}}-C \sum S_{\mathrm{i}} E_{\mathrm{i}}{ }^{2} .
\end{aligned}
$$

However, coefficients $A, B$, and $C$, especially the latter two, would have different values for cations and anions because the orientation of primary solvent molecules on the respective ion surface may be dependent largely on the sign of the local surface field strength, $E_{\mathrm{i}}$ (i.e., positive/negative). This is also the case with positively and negatively charged surfaces of an individual ion. Accordingly, we use two different values for coefficients $B$ and $C$, depending on the sign of $E_{\mathrm{i}}$ :

$$
\begin{array}{r}
\Delta G_{\mathrm{S}}^{\circ}=-A^{\mathrm{S}} \sum S_{\mathrm{i}}-B_{+}^{\mathrm{S}} \sum_{\mathrm{Ei}>0} S_{\mathrm{i}} E_{\mathrm{i}}-C_{+}^{\mathrm{S}} \sum_{\mathrm{Ei}>0} S_{\mathrm{i}} E_{\mathrm{i}}^{2}- \\
B_{-}^{\mathrm{S}} \sum_{\mathrm{Ei}<0} S_{\mathrm{i}} E_{\mathrm{i}}-C_{-}^{\mathrm{S}} \sum_{\mathrm{Ei}<0} S_{\mathrm{i}} E_{\mathrm{i}}^{2},
\end{array}
$$

where the superscript (S) of coefficients $A, B$, and $C$ shows that they depend on the nature of solvent $\mathrm{S}(=\mathrm{O}$ or $\mathrm{W})$, and the subscript (+ or - ) corresponds to the positively or negatively charged surface, respectively.

The transfer energy $\Delta G_{\mathrm{tr}}^{\mathrm{O}, \mathrm{W} \rightarrow \mathrm{O}}$ is defined as the difference between $\Delta G_{\mathrm{O}}^{\circ}$ and $\Delta G_{\mathrm{W}}^{\circ}$ :

$$
\begin{aligned}
\Delta G_{\mathrm{tr}}^{\circ, \mathrm{W} \rightarrow \mathrm{O}}= & \Delta G_{\mathrm{O}}^{\circ}-\Delta G_{\mathrm{W}}^{\circ}=\Delta A \sum S_{\mathrm{i}}+\Delta B_{+} \sum_{\mathrm{Ei}>0} S_{\mathrm{i}} E_{\mathrm{i}}+ \\
& \Delta C_{+} \sum_{\mathrm{Ei}>0} S_{\mathrm{i}} E_{\mathrm{i}}^{2}+\Delta B_{-} \sum_{\mathrm{Ei}<0} S_{\mathrm{i}} E_{\mathrm{i}}+\Delta C_{-} \sum_{\mathrm{Ei}<0} S_{\mathrm{i}} E_{\mathrm{i}}^{2}
\end{aligned}
$$

with $\Delta A=A^{\mathrm{W}}-A^{\mathrm{O}}, \Delta B_{+}=B_{+}^{\mathrm{W}}-B_{+}^{\mathrm{O}}, \Delta C_{+}=C_{+}^{\mathrm{W}}-C_{+}^{\mathrm{O}}, \Delta B_{-}=B_{-}^{\mathrm{W}}-B_{-}^{\mathrm{O}}$, $\Delta C_{-}=C_{-}^{\mathrm{W}}-C_{-}^{\mathrm{O}}$.

However, for organic ions having charged groups, we should take into account the effect of the coextraction of water molecules with the charged groups. In our previous paper, ${ }^{11}$ it was found that negatively charged groups $\left(-\mathrm{SO}_{3}^{-},-\mathrm{CO}_{2}^{-}\right.$, and 
Table 1 Experimental and theoretical values of $\Delta G_{\mathrm{tr}}^{\mathrm{o}, \mathrm{W} \rightarrow \mathrm{O}}$ and $\Delta_{\mathrm{O}}^{\mathrm{W}} \phi^{\circ}$ for the transfer of cations at the DCE/W interface $\left(25^{\circ} \mathrm{C}\right)$

\begin{tabular}{|c|c|c|c|c|c|c|c|}
\hline \multirow{2}{*}{\multicolumn{2}{|c|}{ Cation }} & \multicolumn{3}{|c|}{$\Delta G_{\mathrm{tr}}^{\mathrm{o}} \mathrm{W} \rightarrow \mathrm{O} / \mathrm{kJ} \mathrm{mol}^{-1}$} & \multicolumn{3}{|c|}{$\Delta_{O}^{\mathrm{W}} \phi^{\circ} / \mathrm{V}$} \\
\hline & & Exp. & Theor. $^{\mathrm{a}}$ & Diff. & Exp. & Theor. $^{\mathrm{a}}$ & Diff. \\
\hline 1 & $\mathrm{MeEtNH}_{2}{ }^{+}$ & 30.8 & 29.1 & 1.7 & 0.319 & 0.302 & 0.017 \\
\hline 2 & $\mathrm{Et}_{2} \mathrm{NH}_{2}{ }^{+}$ & 26.7 & 23.7 & 3.0 & 0.277 & 0.246 & 0.031 \\
\hline 3 & $\mathrm{Pr}_{2} \mathrm{NH}_{2}^{+}$ & 21.3 & 17.5 & 3.8 & 0.221 & 0.182 & 0.039 \\
\hline 4 & $\mathrm{Me}_{3} \mathrm{NH}^{+}$ & 25.1 & 23.4 & 1.6 & 0.260 & 0.243 & 0.017 \\
\hline 5 & $\mathrm{MeEt}_{2} \mathrm{NH}^{+}$ & 14.7 & 13.3 & 1.3 & 0.152 & 0.138 & 0.014 \\
\hline 6 & $\mathrm{Et}_{3} \mathrm{NH}^{+}$ & 12.0 & 12.9 & -0.9 & 0.124 & 0.133 & -0.009 \\
\hline 7 & cyc- $\left(\mathrm{C}_{6} \mathrm{H}_{11}\right) \mathrm{CH}_{2} \mathrm{NH}_{3}^{+}$ & 25.6 & 24.9 & 0.7 & 0.265 & 0.258 & 0.007 \\
\hline 8 & $\mathrm{PhCH}_{2} \mathrm{NH}_{3}^{+}$ & 28.7 & 28.6 & 0.0 & 0.297 & 0.297 & 0.000 \\
\hline 9 & $\mathrm{Me}_{4} \mathrm{~N}^{+}$ & 14.8 & 13.6 & 1.2 & 0.153 & 0.141 & 0.012 \\
\hline 10 & $\mathrm{Et}_{4} \mathrm{~N}^{+}$ & 1.9 & 6.6 & -4.7 & $0.020^{\mathrm{b}}$ & 0.068 & -0.048 \\
\hline 11 & $\mathrm{Pr}_{4} \mathrm{~N}^{+}$ & -10.5 & -8.9 & -1.6 & -0.109 & -0.092 & -0.017 \\
\hline 12 & $\mathrm{Bu}_{4} \mathrm{~N}^{+}$ & -25.6 & -29.5 & 3.9 & -0.265 & -0.306 & 0.041 \\
\hline 13 & $\mathrm{MeEt}_{3} \mathrm{~N}^{+}$ & 8.7 & 6.9 & 1.8 & 0.090 & 0.071 & 0.019 \\
\hline 14 & Choline $^{+}$ & 20.2 & 19.6 & 0.5 & 0.209 & 0.203 & 0.006 \\
\hline 15 & 1-Bu-pyridine ${ }^{+}$ & 1.7 & 3.5 & -1.7 & 0.018 & 0.036 & -0.018 \\
\hline 16 & $m-\left(\mathrm{CH}_{3}\right)-1-\mathrm{Bu}-$ pyridine ${ }^{+}$ & -2.7 & 0.2 & -2.9 & -0.028 & 0.002 & -0.030 \\
\hline 17 & $p$ - $\left(\mathrm{CH}_{3}\right)-1-\mathrm{Bu}-$ pyridine ${ }^{+}$ & -4.2 & 0.4 & -4.6 & -0.044 & 0.004 & -0.048 \\
\hline 18 & Acebutolol $^{+}$ & 8.6 & 10.5 & -1.9 & 0.089 & 0.109 & -0.020 \\
\hline 19 & Alprenolol $^{+}$ & 9.8 & 10.1 & -0.4 & 0.101 & 0.105 & -0.004 \\
\hline 20 & Desipramine $^{+}$ & 1.3 & 2.1 & -0.8 & 0.013 & 0.022 & -0.009 \\
\hline 21 & Diltiazem $^{+}$ & -10.9 & -9.8 & -1.1 & -0.113 & -0.102 & -0.011 \\
\hline 22 & Imipramine $^{+}$ & -7.0 & -7.2 & 0.1 & -0.073 & -0.074 & -0.001 \\
\hline 23 & Labetalol $^{+}$ & 18.2 & 21.4 & -3.2 & 0.189 & 0.222 & -0.033 \\
\hline 24 & $\mathrm{Nadolol}^{+}$ & 27.3 & 26.9 & 0.4 & 0.283 & 0.279 & 0.004 \\
\hline 25 & Propranolol $^{+}$ & 9.9 & 11.2 & -1.2 & 0.103 & 0.116 & -0.013 \\
\hline 26 & Verapamil $^{+}$ & -7.3 & -12.3 & 4.9 & -0.076 & -0.127 & 0.051 \\
\hline
\end{tabular}

a. Obtained from Eq. (12) with the combination of MK-vdW and with $\xi_{+}=+20 \mathrm{~V} \mathrm{~nm}^{-1}$. b. From Ref. 37 .

$-\mathrm{O}^{-}$) for organic anions or positively charged groups (primary to tertiary ammonium groups) for organic cations coextract some water molecules (in the NB/W system), and also that the number of coextracted water molecules depends on the averaged electric field strength on oxygen or hydrogen atoms of the charged groups. Furthermore, it was revealed that there is a threshold value of the electric field, above which the coextraction of water occurs. On the basis of these findings, we divided the negatively charged surface of an anion into "hydrated" and "non-hydrated" surfaces and also the positively charged surface of a cation in the same manner. Eventually, Eq. (11) has been further modified as follows:

For cations:

$$
\begin{aligned}
\Delta G_{\mathrm{tr}}^{\mathrm{O}}, \mathrm{W} \rightarrow \mathrm{O}= & \Delta A \sum S_{\mathrm{i}}+\Delta B^{*} \sum_{\mathrm{Ei} 2 \xi} S_{\mathrm{i}} E_{\mathrm{i}}+\Delta C^{*} \sum_{\mathrm{Ei}>\xi_{5}} S_{\mathrm{i}} E_{\mathrm{i}}^{2}+ \\
& \Delta B_{+} \sum_{\xi_{+}>\mathrm{Ei}>0} S_{\mathrm{i}} E_{\mathrm{i}}+\Delta C_{+} \sum_{\xi_{+}>\mathrm{Ei}>0} S_{\mathrm{i}} E_{\mathrm{i}}^{2}+ \\
& \Delta B_{-} \sum_{\mathrm{Ei}<0} S_{\mathrm{i}} E_{\mathrm{i}}+\Delta C_{+} \sum_{\mathrm{Ei}<0} S_{\mathrm{i}} E_{\mathrm{i}}^{2} .
\end{aligned}
$$

For anions:

$$
\begin{aligned}
\Delta G_{\mathrm{tr}}^{\mathrm{o}, \mathrm{W} \rightarrow \mathrm{O}=} & \Delta A \sum S_{\mathrm{i}}+\Delta B^{*} \sum_{\mathrm{Ei}<\xi} S_{\mathrm{i}} E_{\mathrm{i}}+\Delta C^{*} \sum_{\mathrm{Ei}<\xi} S_{\mathrm{i}} E_{\mathrm{i}}^{2}+ \\
& \Delta B_{+} \sum_{\mathrm{Ei}>0} S_{\mathrm{i}} E_{\mathrm{i}}+\Delta C_{+} \sum_{\mathrm{Ei}>0} S_{\mathrm{i}} E_{\mathrm{i}}{ }^{2}+ \\
& \Delta B_{-} \sum_{\xi<<\mathrm{Ei}<0} S_{\mathrm{i}} E_{\mathrm{i}}+\Delta C_{+} \sum_{\xi<<\mathrm{Ei}<0} S_{\mathrm{i}} E_{\mathrm{i}}{ }^{2} .
\end{aligned}
$$

In each equation, an asterisk in $\Delta B^{*}\left(=B^{*, \mathrm{~W}}-B^{*, \mathrm{O}}\right)$ or $\Delta C^{*}$ $\left(=C^{*, \mathrm{~W}}-C^{*, \mathrm{O}}\right)$ indicates the "hydrated" ionic surface with $E_{\mathrm{i}} \geq \xi_{+}$or $E_{\mathrm{i}} \leq \xi_{-}$, where $\xi_{+}$or $\xi_{-}$is the respective threshold value. Thus, the effect of the coextraction of water is incorporated in the coefficients $\Delta B^{*}$ and $\Delta C^{*}$. Basically it is impossible to obtain any rigorous theoretical values of the coefficients such as $\Delta A, \Delta B^{*}, \Delta C_{+}$, etc. In the present as well as previous studies, we performed regression analyses with experimental data to determine the coefficients as adjusting parameters.

\section{Calculation Methods}

DFT calculations were performed using the Gaussian 09 program package. Using the B3LYP hybrid DFT method with the $6-311++\mathrm{G}(2 \mathrm{~d}, \mathrm{p})$ basis set, geometries of ions in vacuum were optimized and partial atomic charges were computed by three different methods, Mulliken, ${ }^{31}$ Merz-Kollman ${ }^{32,33}$ (MK), and natural population analysis ${ }^{34}$ (NPA). The numerical sums in Eqs. (12) and (13) \{e.g., $\sum S_{\mathrm{i}}, \sum_{\mathrm{Ei} z \xi_{+}} S_{\mathrm{i}} E_{\mathrm{i}}, \sum_{\mathrm{Ei} z \xi_{+}} S_{\mathrm{i}} E_{\mathrm{i}}^{2}$, etc. in Eq. (12) $\}$ were then obtained by using the previously reported subprogram. ${ }^{9}$ In the subprogram, $E_{\mathrm{i}}$ can be obtained on the van der Waals (vdW) surface of an ion and on the solvent-accessible surface $^{35,36}$ (SAS) being apart from the vdW surface by $0.14 \mathrm{~nm}$ ( $=$ the radius of water molecule). For further details, see the previous paper. ${ }^{9}$

\section{Experimental Data}

In this study, the $\Delta_{O}^{\mathrm{W}} \phi^{\circ}$ values for 26 cations and 24 anions have been determined by means of ion-transfer voltammetry (for experimental details, see Supporting Information). The experimental values of $\Delta_{O}^{\mathrm{W}} \phi^{\circ}$ and $\Delta G_{\mathrm{tr}}^{\mathrm{o}, \mathrm{W} \rightarrow \mathrm{O}}$ for anions and cations are shown in Tables 1 and 2, respectively, together with the literature values ${ }^{37}$ for reference ions $\left(\mathrm{Et}_{4} \mathrm{~N}^{+}\right.$and $\left.\mathrm{ClO}_{4}^{-}\right)$. The group of cations includes nine protonated amine drugs (18 - 26), which were reported for their parallel artificial membrane permeability. ${ }^{38}$ The $\Delta_{O}^{\mathrm{W}} \phi^{\circ}$ values of these drug ions at the 
Table 2 Experimental and theoretical values of $\Delta G_{\mathrm{tr}}^{\mathrm{o}} \mathrm{W} \rightarrow \mathrm{O}$ and $\Delta_{\mathrm{O}}^{\mathrm{W}} \phi^{\circ}$ for the transfer of anions at the DCE/W interface $\left(25^{\circ} \mathrm{C}\right)$

\begin{tabular}{|c|c|c|c|c|c|c|c|}
\hline & \multirow{2}{*}{ Anion } & \multicolumn{3}{|c|}{$\Delta G_{\mathrm{tr}}^{\mathrm{o}} \mathrm{W} \rightarrow \mathrm{O} / \mathrm{kJ} \mathrm{mol}^{-1}$} & \multicolumn{3}{|c|}{$\Delta_{O}^{\mathrm{W}} \phi^{\circ} / \mathrm{V}$} \\
\hline & & Exp. & Theor. $^{a}$ & Diff. & Exp. & Theor. $^{a}$ & Diff. \\
\hline 27 & $\mathrm{ClO}_{4}^{-}$ & 16.4 & 18.2 & -1.8 & $-0.17^{b}$ & -0.188 & 0.018 \\
\hline 28 & $\mathrm{PhSO}_{3}^{-}$ & 31.2 & 29.5 & 1.6 & -0.323 & -0.306 & -0.017 \\
\hline 29 & $p-\left(\mathrm{CH}_{3}\right) \mathrm{PhSO}_{3}^{-}$ & 29.4 & 28.2 & 1.2 & -0.305 & -0.293 & -0.012 \\
\hline 30 & $o, o, p-\left(\mathrm{CH}_{3}\right)_{3} \mathrm{PhSO}_{3}^{-}$ & 24.0 & 21.3 & 2.8 & -0.249 & -0.220 & -0.029 \\
\hline 31 & $m-\left(\mathrm{NO}_{2}\right) \mathrm{PhSO}_{3}^{-}$ & 23.0 & 26.6 & -3.6 & -0.238 & -0.276 & 0.038 \\
\hline 32 & $o, p-\left(\mathrm{NO}_{2}\right)_{2} \mathrm{PhSO}_{3}^{-}$ & 15.6 & 14.2 & 1.4 & -0.162 & -0.148 & -0.014 \\
\hline 33 & $o, o, p-\left(\mathrm{NO}_{2}\right)_{3} \mathrm{PhSO}_{3}^{-}$ & 3.0 & 4.9 & -2.0 & -0.031 & -0.051 & 0.020 \\
\hline 34 & $2-\left(\mathrm{NH}_{2}\right), 5-\left(\mathrm{NO}_{2}\right) \mathrm{PhSO}_{3}^{-}$ & 24.4 & 21.6 & 2.8 & -0.253 & -0.224 & -0.029 \\
\hline 35 & $p$-(NHPh) $\mathrm{PhSO}_{3}^{-}$ & 21.1 & 23.1 & -1.9 & -0.219 & -0.239 & 0.020 \\
\hline 36 & 1-NaphSO ${ }_{3}^{-}$ & 21.5 & 24.1 & -2.6 & -0.223 & -0.250 & 0.027 \\
\hline 37 & 2-NaphSO ${ }_{3}^{-}$ & 21.0 & 26.1 & -5.1 & -0.218 & -0.271 & 0.053 \\
\hline 38 & $n-\left(\mathrm{C}_{12} \mathrm{H}_{25}\right) \mathrm{OSO}_{3}^{-}$ & 1.8 & 4.2 & -2.4 & -0.019 & -0.044 & 0.025 \\
\hline 39 & $o, p-\left(\mathrm{NO}_{2}\right)_{2} \mathrm{PhCH}_{2} \mathrm{CO}_{2}^{-}$ & 32.4 & 23.5 & 9.0 & -0.336 & -0.243 & -0.093 \\
\hline 40 & 2-NaphCO ${ }_{2}^{-}$ & 29.5 & 33.0 & -3.4 & -0.306 & -0.342 & 0.036 \\
\hline 41 & 3-(OH),2-NaphCO ${ }_{2}^{-}$ & 16.4 & 22.3 & -5.9 & -0.170 & -0.231 & 0.061 \\
\hline 42 & $n-\left(\mathrm{C}_{12} \mathrm{H}_{23}\right) \mathrm{CO}_{2}^{-}$ & 21.1 & 24.8 & -3.7 & -0.219 & -0.257 & 0.038 \\
\hline 43 & $\mathrm{CH}_{3}\left(\mathrm{CH}_{2}\right)_{7}=\left(\mathrm{CH}_{2}\right)_{7} \mathrm{CO}_{2}^{-}$ & 17.2 & 12.5 & 4.7 & -0.178 & -0.129 & -0.049 \\
\hline 44 & $N$-lauroylsarcosinate ${ }^{-}$ & 20.2 & 19.9 & 0.3 & -0.209 & -0.206 & -0.003 \\
\hline 45 & $o-\left(\mathrm{NO}_{2}\right) \mathrm{PhO}^{-}$ & 26.7 & 21.0 & 5.7 & -0.277 & -0.218 & -0.059 \\
\hline 46 & $m-\left(\mathrm{NO}_{2}\right) \mathrm{PhO}^{-}$ & 28.4 & 26.6 & 1.8 & -0.294 & -0.276 & -0.018 \\
\hline 47 & $o, p-\left(\mathrm{NO}_{2}\right)_{2} \mathrm{PhO}^{-}$ & 14.2 & 14.8 & -0.6 & -0.147 & -0.154 & 0.007 \\
\hline 48 & $o, o, p-\left(\mathrm{NO}_{2}\right)_{3} \mathrm{PhO}^{-}$ & 4.7 & 8.8 & -4.0 & -0.049 & -0.091 & 0.042 \\
\hline 49 & $o, o, p-\mathrm{Br}_{3} \mathrm{PhO}^{-}$ & 13.4 & 10.6 & 2.9 & -0.139 & -0.109 & -0.030 \\
\hline $\mathbf{5 0}$ & $o-\left(\mathrm{NH}_{2}\right), p-\left(\mathrm{NO}_{2}\right) \mathrm{PhO}^{-}$ & 28.7 & 25.6 & 3.0 & -0.297 & -0.266 & -0.031 \\
\hline
\end{tabular}

a. Obtained from Eq. (13) with the combination of MK-vdW and with $\xi_{-}=-29 \mathrm{~V} \mathrm{~nm}^{-1}$. b. From Ref. 37.

DCE/W interface were already reported in our previous paper. ${ }^{39}$ However, even considering the difference in the supporting electrolyte used in DCE, there are considerably large differences between the previous and present values of $\Delta_{O}^{\mathrm{W}} \phi^{\circ}$ (in particular for 18 and 20; most probably, their $\Delta_{O}^{\mathrm{W}} \phi^{\circ}$ values were misreported in the previous paper ${ }^{39}$ ). Therefore, we would like to revise the previous values for $\mathbf{1 8}$ - $\mathbf{2 6}$ to those shown in Table 1.

\section{Results and Discussion}

Multivariate regression analyses were performed on the experimental data of $\Delta G_{\mathrm{tr}}^{\mathrm{o}, \mathrm{W} \rightarrow \mathrm{O}}$ for cations and anions (Tables 1 and 2) to determine the coefficients in Eqs. (12) and (13), respectively. The numerical sums required for the regression were obtained from the above-described quantum-chemical calculation (vide supra). In the present analysis, we investigated the performance of regression analysis in all combinations of three different atomic charges (Mulliken, MK, and NPA) with two different molecular surfaces (vdW and SAS). Furthermore, in the respective six combinations, the value of $\xi_{+}$or $\xi_{-}$was optimized for cations in a certain range (e.g., +6 to $+35 \mathrm{~V} \mathrm{~nm}^{-1}$ on vdW surface) or likewise for anions $\left(-8\right.$ to $\left.-32 \mathrm{~V} \mathrm{~nm}^{-1}\right)$, respectively.

As shown in Fig. S2 (Supporting Information), the highest performance was obtained when using the combination of MK-vdW for both cations and anions. This is in line with the previous result for cations in the NB/W system, ${ }^{9}$ however not with that for anions (with the best combination being NPA-SAS; the origin of this difference is unclear at the present time). In the present DCE/W system, the optimized values of $\xi_{+}$and $\xi_{-}$ (for $\mathrm{MK}-\mathrm{vdW}$ ) were $+20 \mathrm{~V} \mathrm{~nm}^{-1}$ or $-29 \mathrm{~V} \mathrm{~nm}^{-1}$, respectively. The optimized coefficients are summarized in Table 3. Figure S3 (Supporting Information) shows a good linear
Table 3 Optimized coefficients in Eqs. (12) and (13) and performance of regression analyses

\begin{tabular}{cccccc}
\hline \multirow{2}{*}{ Coefficient } & \multicolumn{2}{c}{ In Eq. (12) (for cations) } & & \multicolumn{2}{c}{ In Eq. (13) (for anions) } \\
\cline { 2 - 3 } \cline { 5 - 6 } \cline { 5 - 6 } & Optimized $^{\mathrm{a}}$ & $\mathrm{SD}^{\mathrm{b}}$ & & Optimized $^{\mathrm{a}}$ & SD $^{\mathrm{b}}$ \\
\hline$\Delta A$ & -33.83 & 4.1 & & -12.42 & 2.2 \\
$\Delta B^{*}$ & 3.302 & 1.7 & & -0.3177 & 1.2 \\
$\Delta C^{*}$ & 0.03267 & 0.049 & & 0.08588 & 0.035 \\
$\Delta B_{+}$ & 6.767 & 1.1 & & 0.7680 & 2.9 \\
$\Delta C_{+}$ & -0.2562 & 0.065 & & -0.06480 & 0.19 \\
$\Delta B_{-}$ & -3.714 & 1.5 & & -1.054 & 0.67 \\
$\Delta C_{-}$ & 0.001908 & 0.076 & & 0.02103 & 0.031 \\
$n^{\mathrm{c}}$ & 26 & & & 24 & \\
$R^{2 \mathrm{~d}}$ & 0.980 & & & 0.973 & \\
$\mathrm{MAE}^{\mathrm{e}}$ & 1.9 & & 3.1 & \\
\hline
\end{tabular}

a. Optimized values with $\xi_{+}=+20 \mathrm{~V} \mathrm{~nm}^{-1}$ (cations) or $\xi_{-}=-29 \mathrm{~V} \mathrm{~nm}^{-1}$ (anions).

b. Standard deviations.

c. Number of data.

d. Square of the correlation coefficient.

e. In $\mathrm{kJ} \mathrm{mol}^{-1}$.

dependence of the experimental values of $\Delta G_{\mathrm{tr}}^{\mathrm{o}} \mathrm{W} \rightarrow \mathrm{O}$ for cations and anions against the theoretical values obtained with Eqs. (12) and (13). As shown in Table 3, the MAE values are as small as 1.9 and $3.1 \mathrm{~kJ} \mathrm{~mol}^{-1}$ for the cations and anions, respectively, which correspond to the error of $20-30 \mathrm{mV}$ in $\Delta_{O}^{\mathrm{W}} \phi^{\circ} .{ }^{40}$ Considering the typical error of voltammetric measurements $(\sim 10 \mathrm{mV})$, it has been suggested that the non-Bornian model is available for accurate and reliable prediction of $\Delta G_{\mathrm{tr}^{\circ}}^{\mathrm{o}, \mathrm{W} \rightarrow \mathrm{O}}$ or $\Delta_{O}^{\mathrm{W}} \phi^{\circ}$ in the DCE/W system. It should be here noted that the $\mathrm{DCE} / \mathrm{W}$ system has been claimed to be more suitable for 

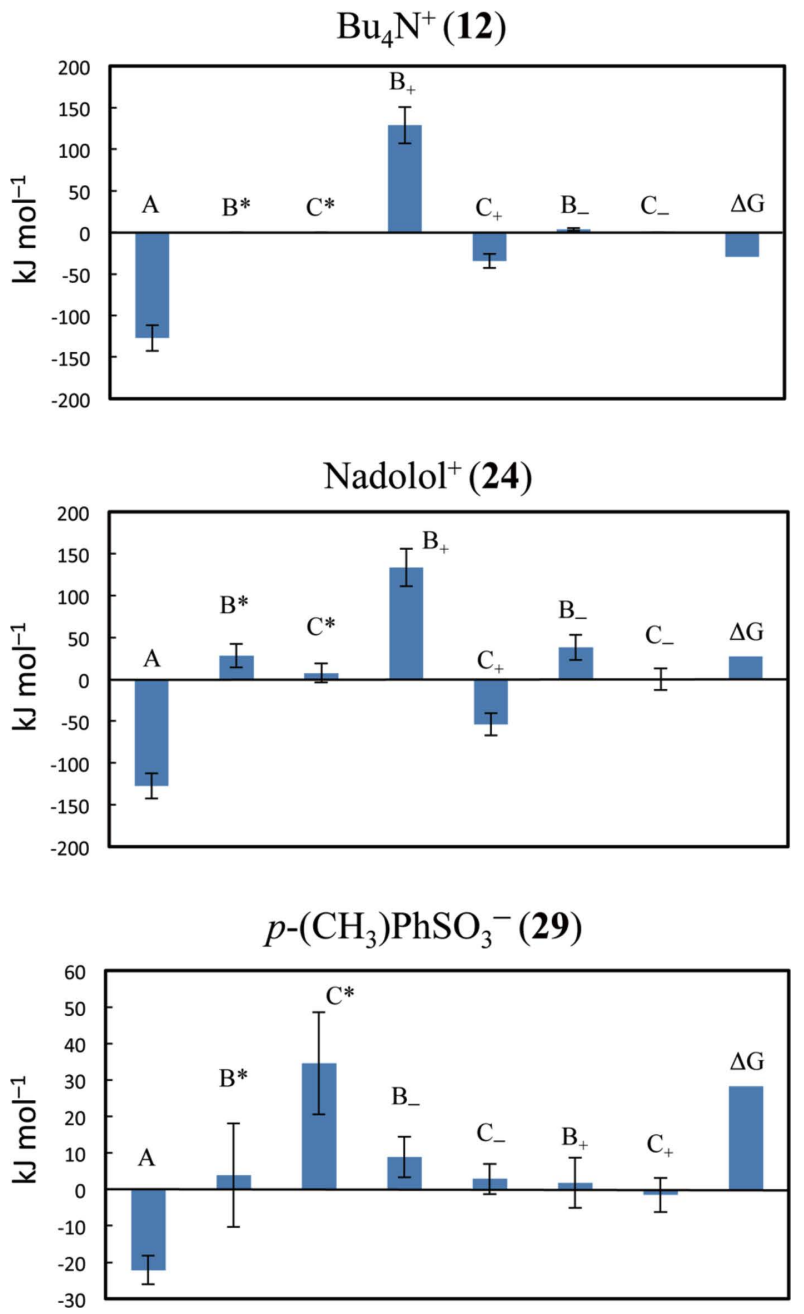

Fig. 1 Energy decomposition of $\Delta G_{\mathrm{tr}}^{\mathrm{o}, \mathrm{W} \rightarrow \mathrm{O}}$ for three representative ions, 12, 24, and 29. The respective terms in the r.h.s. of Eqs. (12) and (13) are shown by bars. The error bars represent the SD of the respective energies.

prediction of drug membrane permeability than the conventional 1-octanol/W system. ${ }^{39,41,42}$ This pharmaceutical application is currently in progress.

In this paper, we have performed energy decomposition of $\Delta G_{\mathrm{tr}}^{\mathrm{o}, \mathrm{W} \rightarrow \mathrm{O}}$ for ions. Figure 1 shows the results for three representative ions $(\mathbf{1 2}, \mathbf{2 4}$, and $\mathbf{2 9})$, in which the energies given by the respective terms in the r.h.s. of Eq. (12) or (13) are shown by bars. In the figure and subsequent ones, the first to seventh terms and the total energy (i.e., $\Delta G_{\mathrm{tr}}^{\mathrm{o}, \mathrm{W} \rightarrow \mathrm{O}}$ ) are denoted by $\mathrm{A}, \mathrm{B}^{*}$, $\mathrm{C}^{*}, \mathrm{~B}_{+}, \mathrm{C}_{+}, \mathrm{B}_{-}, \mathrm{C}_{-}$, and $\Delta \mathrm{G}$, respectively.

For $12\left(\mathrm{Bu}_{4} \mathrm{~N}^{+}\right)$, the contributions from $\mathrm{B}^{*}, \mathrm{C}^{*}, \mathrm{~B}_{-}$, and $\mathrm{C}_{-}$are close to zero, since the ion does not have either a charged group or negatively charged surface. On the other hand, the contributions from $\mathrm{A}$ and $\mathrm{B}_{+}$are significant, respectively, suggesting the large hydrophobic interaction (the so-called cavity formation energy) and the actually large ion-dipole (water) interaction. These two positively and negatively large contributions $\left(\sim 100 \mathrm{~kJ} \mathrm{~mol}^{-1}\right)$ are almost cancelled out for this ion, and the contribution from $\mathrm{C}_{+}$determines the total energy $(\Delta \mathrm{G})$ of $-29.5 \mathrm{~kJ} \mathrm{~mol}^{-1}$.

A cationic drug ion, 24 (nadolol $^{+}$), having a charged group $\left(-\mathrm{NH}_{2}{ }^{+}\right)$shows a certain contribution from $\mathrm{B}^{*}$, though the contribution from $\mathrm{C}^{*}$ is negligible. Since this ion has three

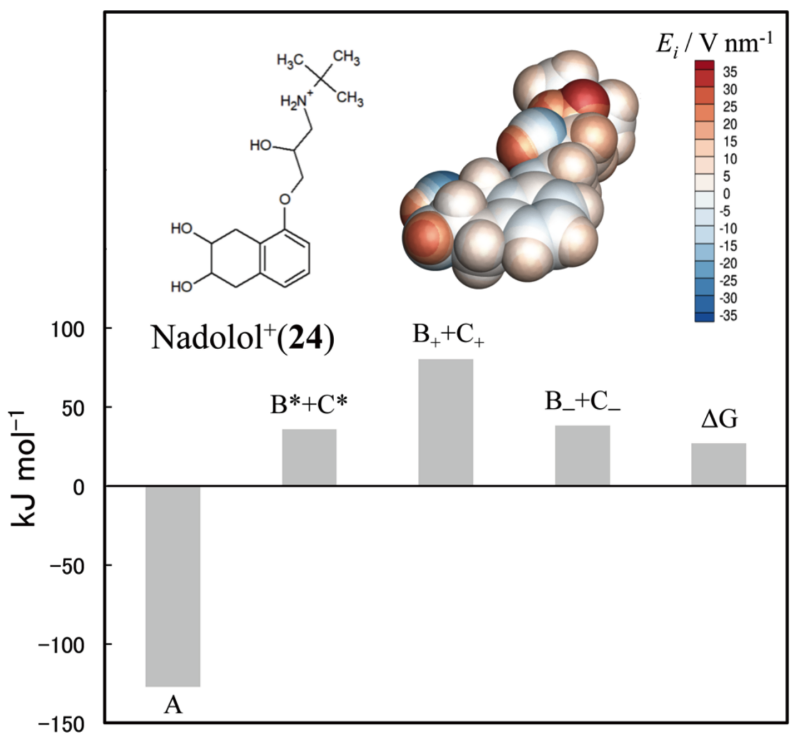

Fig. 2 Energy decomposition of $\Delta G_{\mathrm{tr}}^{\mathrm{o}, \mathrm{W} \rightarrow \mathrm{O}}$ for $\mathbf{2 4}$. The three different sums of B-and C-terms are shown with the A-term and the total $\Delta \mathrm{G}$. The inset shows the chemical structure and the optimized structure of the ion and also the distribution of $E_{\mathrm{i}}$ at the vdW surface.

hydroxy groups charged negatively, we find some contribution from $\mathrm{B}_{-}$(though not from $\mathrm{C}_{-}$). Because of this contribution, the $\Delta \mathrm{G}$ for 24 has a positive value $\left(+26.9 \mathrm{~kJ} \mathrm{~mol}^{-1}\right)$.

An organic anion, 29, having a sulfonate group $\left(-\mathrm{SO}_{3}{ }^{-}\right)$, shows a prominent contribution from $\mathrm{C}^{*}$, though the contribution from $\mathrm{B}^{*}$ is small. This suggests that the strongly charged surface of the sulfonate group should mainly contribute to the hydrophilic nature of the anion, i.e., the positively large $\Delta \mathrm{G}\left(+28.2 \mathrm{~kJ} \mathrm{~mol}^{-1}\right)$.

As exemplified by the above three ions, the energy decomposition analysis enables us to discuss the respective contributions from the different terms in Eq. (12) or (13) to the total $\Delta \mathrm{G}$. However, as seen in Fig. 1, the magnitude relation between a $\mathrm{B}_{-}$term $\left(\mathrm{B}^{*}, \mathrm{~B}_{+}\right.$, or $\left.\mathrm{B}_{-}\right)$and a $\mathrm{C}$-term $\left(\mathrm{C}^{*}, \mathrm{C}_{+}\right.$, or $\mathrm{C}_{-}$, respectively) is complicated. For example, the $\mathrm{B}^{*}$ term for cations is usually larger than the $\mathrm{C}^{*}$-term (e.g., see $\mathbf{2 4}$ in Fig. 1), however the situation is reverse in the case of anions (e.g., 29). In some cases, a $\mathrm{C}$-term shows a negative contribution to the total $\Delta \mathrm{G}$ (e.g., the $\mathrm{C}_{+}$-term for $\mathbf{2 4}$ ). These complicated dependences of B-term and $\mathrm{C}$-term have not fully been elucidated at the present time. Nevertheless, the respective sums of $\mathrm{B}_{\text {-term }}$ and $\mathrm{C}$-term (i.e., $\mathrm{B}^{*}+\mathrm{C}^{*}, \mathrm{~B}_{+}+\mathrm{C}_{+}$, or $\mathrm{B}_{-}+\mathrm{C}_{-}$) would show effects of the electric field $\left(E_{\mathrm{i}}\right)$ for three different surfaces of an ion, i.e., the strongly charged "hydrated" surface and the positively and negatively charged "non-hydrated" surfaces. Since these electrified surfaces are commonly hydrophilic, it is expected that all the sums, $\mathrm{B}^{*}+\mathrm{C}^{*}, \mathrm{~B}_{+}+\mathrm{C}_{+}$, and $\mathrm{B}_{-}+\mathrm{C}_{-}$, will show some positive effects to $\Delta \mathrm{G}$. Figure 2 shows a typical example for $\mathbf{2 4}$; in the inset, the chemical structure and the optimized structure of the ion and also the distribution of $E_{\mathrm{i}}$ at the vdW surface are shown. The three different surfaces corresponding to $\mathrm{B}^{*}+\mathrm{C}^{*}$ (for $\left.E_{\mathrm{i}}>\xi_{+}\right), \mathrm{B}_{+}+\mathrm{C}_{+}\left(\right.$for $\xi_{+}>E_{\mathrm{i}}>0$ ), and $\mathrm{B}_{-}+\mathrm{C}_{-}$(for $E_{\mathrm{i}}<0$ ) can be identified by the color of the ion surface.

In this study, we have made an additional regression analysis by combining the two data sets for cations (Table 1) and anions (Table 2). In this case, $\Delta B^{*} \sum S_{\mathrm{i}} E_{\mathrm{i}}$ and $\Delta C^{*} \sum S_{\mathrm{i}} E_{\mathrm{i}}{ }^{2}$ terms for "hydrated" surfaces in Eq. (12) or (13) have been divided into two, respectively, for positively and negatively charged surfaces, 
so that the regression equation has as many as nine terms with the coefficients of $\Delta A, \Delta B_{+}^{*}, \Delta C_{+}^{*}, \Delta B_{-}^{*}, \Delta C_{-}^{*}, \Delta B_{+}, \Delta C_{+}, \Delta B_{-}$, and $\Delta C_{+}$. In Supporting Information, the regression equation (Eq. (S1)) and the optimized coefficients etc. (Table S1) are shown. The regression performance $\left(R^{2}=0.942\right.$; MAE $=3.9 \mathrm{~kJ}$ $\mathrm{mol}^{-1}$ ) is slightly worse than those of the above individual regression analyses for cations and anions, but would be promising for the prediction of $\Delta G_{\mathrm{tr}}^{\mathrm{o}, \mathrm{W} \rightarrow \mathrm{O}}$ for neutral molecules or zwitterions.

\section{Concluding Remarks}

The $\Delta G_{\mathrm{tr}}^{\mathrm{o}, \mathrm{W} \rightarrow \mathrm{O}}$ values for organic cations and anions in the DCE/W system could be determined by ion-transfer voltammetry with a micro $\mathrm{O} / \mathrm{W}$ interface under the condition that the concentration of supporting electrolyte in $\mathrm{O}$ was low (i.e., $1.0 \mathrm{mM}$ ). The non-Bornian solvation model was successfully applied to obtain semi-empirical equations that would be useful for the prediction of $\Delta G_{\mathrm{tr}}^{\mathrm{o}, \mathrm{W} \rightarrow \mathrm{O}}$ for cations and anions. The energy decomposition analysis is useful for discussing quantitatively different contributions to $\Delta G_{\mathrm{tr}}^{\mathrm{o}, \mathrm{W} \rightarrow \mathrm{O}}$ of an ion from the hydrophilic interactions on the "hydrated" and positively and negatively charged "non-hydrated" surfaces as well as from the hydrophobic interaction (cavity formation energy).

\section{Supporting Information}

Experimental details (including cyclic voltammograms shown in Fig. S1), comparison of the performance of regression analyses, scatter plots of the theoretical and experimental values of $\Delta G_{\mathrm{tr}}^{\mathrm{o}, \mathrm{W} \rightarrow \mathrm{O}}$, and the regression analysis by combining the data sets of cations and anions. This material is available free of charge on the Web at http://www.jsac.or.jp/analsci/.

\section{References and Notes}

1. "Liquid-Liquid Interfaces, Theory and Methods", ed. A. G. Volkov and D. W. Deamer, 1996, CRC Press, Boca Raton, FL.

2. "Liquid Interfaces in Chemical, Biological, and Pharmaceutical Applications", ed. A. G. Volkov, 2001, Marcel Dekker, New York.

3. M. Born, Z. Phys., 1920, 1, 45.

4. M. H. Abraham and J. Liszi, J. Inorg. Nucl. Chem., 1981, 43, 143.

5. A. A. Kornyshev and A. G. Volkov, J. Electroanal. Chem. Interfacial Electrochem., 1984, 180, 363.

6. V. S. Markin and A. G. Volkov, Electrochim. Acta, 1989, 34, 93.

7. T. Osakai and K. Ebina, J. Phys. Chem. B, 1998, 102, 5691 (Erratum: J. Phys. Chem. B, 2015, 119, 13472).

8. W. Murakami, K. Eda, M. Yamamoto, and T. Osakai, J. Electroanal. Chem., 2013, 704, 38.

9. T. Osakai, Y. Naito, K. Eda, and M. Yamamoto, J. Phys. Chem. B, 2015, 119, 13167.

10. T. Osakai, A. Ogata, and K. Ebina, J. Phys. Chem. B, 1997, $101,8341$.

11. Y. Naito, W. Murakami, and K. Eda, M. Yamamoto, and T. Osakai, J. Phys. Chem. B, 2015, 119, 6010.
12. W. Murakami, M. Yamamoto, K. Eda, and T. Osakai, RSC Adv., 2014, 4, 27634.

13. G. Geblewicz and D. J. Schiffrin, J. Electroanal. Chem., 1988, 244, 27.

14. M. Suzuki, M. Matsui, and S. Kihara, J. Electroanal. Chem., 1997, 438, 147.

15. J. Zhang, A. L. Barker, and P. R. Unwin, J. Electroanal. Chem., 2000, 483, 95.

16. T. Osakai, M. Okamoto, T. Sugihara, and K. Nakatani, $J$. Electroanal. Chem., 2009, 628, 27.

17. S. Watariguchi, M. Fujimori, K. Atsumi, and T. Hinoue, Anal. Sci., 2016, 32, 463.

18. T. Kakiuchi, Y. Takasu, and M. Senda, Anal. Chem., 1992, 64, 3096.

19. D. A. Higgins and R. M. Corn, J. Phys. Chem., 1993, 97, 489.

20. H. Nagatani, R. A. Iglesias, D. J. Fermín, P.-F. Brevet, and H. H. Girault, J. Phys. Chem. B, 2000, 104, 6869.

21. T. Osakai, H. Yamada, H. Nagatani, and T. Sagara, J. Phys. Chem. C, 2007, 111, 9480.

22. V. Mareček, A. H. De Armond, and M. K. De Armond, J. Am. Chem. Soc., 1989, 111, 2561.

23. N. A. Kotov and M. G. Kuzmin, J. Electroanal. Chem. Interfacial Electrochem., 1990, 285, 223.

24. H. Nagatani, S. Dejima, H. Hotta, T. Ozeki, and T. Osakai, Anal. Sci., 2004, 20, 1575.

25. T. Kubo, M. Ashida, S. Otagiri, H. Nozue, S. Makigaki, and T. Hinoue, Anal. Sci., 2017, 33, 1407.

26. H. H. Uhlig, J. Phys. Chem., 1937, 41, 1215.

27. J. N. Israelachvili, "Intermolecular and Surface Forces", 3rd ed., 2011, Chap. 17, Academic Press, London.

28. K. Kitaura and K. Morokuma, Int. J. Quantum. Chem., 1976, 10, 325 .

29. H. Umeyama and K. Morokuma, J. Am. Chem. Soc., 1977, 99, 1316.

30. A. Karpfen and P. Schuster, "The Chemical Physics of Solvation, Part A”, ed. R. R. Dogonadze, E. Kálmán, A. A. Kornyshev, and J. Ulstrup, 1985, Chap. 7, Elsevier, Amsterdam.

31. R. S. Mulliken, J. Chem. Phys., 1955, 23, 1833.

32. B. H. Besler, K. M. Merz, and P. A. Kollman, J. Comput. Chem., 1990, 11, 431.

33. U. C. Singh and P. A. Kollman, J. Comput. Chem., 1984, 5, 129.

34. A. E. Reed, L. A. Curtiss, and F. Weinhold, Chem. Rev., 1988, $88,899$.

35. B. Lee and F. M. Richards, J. Mol. Biol., 1971, 55, 379.

36. A. Shrake and J. A. Rupley, J. Mol. Biol., 1973, 79, 351.

37. T. Wandlowski, V. Mareček, and Z. Samec, Electrochim. Acta, 1990, 35, 1173.

38. M. Fujikawa, R. Ano, K. Nakao, R. Shimizu, and M. Akamatsu, Bioorg. Med. Chem., 2005, 13, 4721.

39. M. Nakamura and T. Osakai, J. Electroanal. Chem., 2016, 779, 55.

40. For a few ions (such as $\mathbf{3 9}$ and $\mathbf{4 1}$ ) the theoretical values of $\Delta_{O}^{\mathrm{W}} \phi^{\circ}$ deviate from the experimental values by more than $60 \mathrm{mV}$. The origin of this discrepancy is not clear at the present stage.

41. K. Kontturi and L. Murtomäki, J. Pharm. Sci., 1992, 81, 970 .

42. A. Mälkiä, K. Kontturi, L. Murtomäki, A. Urtti, and A. Kontturi, Eur. J. Pharm. Sci., 2004, 23, 13. 